\title{
Letters
}

Website: bmj.com

\section{Prevention and cure of type 2 diabetes}

\section{General practitioners are treating more} cases of diabetes

EDITOR-Most studies measuring the prevalence of diabetes have been carried out in one locality and have generally measured point prevalences. Hence, although the prevalence of diabetes in England and Wales is increasing, ${ }^{1}$ time trend data on prevalence and future projections based on sound data are both lacking. We recently estimated the prevalence of diabetes in England and Wales between 1994 and 1998 using data from 210 general practices with a combined list size of 1.2 million. $^{2}$

We found that the overall prevalence of diabetes during this period increased from $1.99 \%$ to $2.43 \%$ in males and from $1.69 \%$ to $2.04 \%$ in females. This striking increase in the prevalence of diabetes in primary care is likely to be due to a combination of factors, including better case ascertainment, rising rates of obesity, an ageing population, and an increase in both the size and average age of the ethnic minority population. Overall, $29 \%, 48 \%$, and $24 \%$ of males with diabetes and $26 \%, 48 \%$, and $26 \%$ of females with diabetes were treated by diet, oral hypoglycaemic drugs alone, and insulin respectively.

We estimated around 1.15 million people had a diagnosis of diabetes mellitus in England and Wales in 1998. If the age specific prevalence of diabetes increases by a modest $30 \%$ over the next 25 years (less than predicted by many authorities), then the number of people with diabetes will increase by $70 \%$, to 1.96 million by 2023 . If age specific prevalence increases by more than $30 \%$, then the increase in the number of cases will be even larger.

Our findings illustrate the potential size of the diabetes epidemic facing England and Wales. The epidemic will have major

\section{Advice to authors}

We would like to receive all responses electronically at our website. Please send your letter directly to bmj.com as a rapid response to a published article.

All rapid responses will be considered for publication in the paper journal; authors will be notified by email if their rapid response has been accepted, but not otherwise.

For more detailed advice please see bmj.com/advice/sections.shtm\#letters

bmj.com implications for the NHS, which will have to provide diabetic services for these patients, as well as deal with the clinical and psychosocial complications resulting from diabetes. We therefore reinforce the need to tackle the underlying causes of this epidemic, particularly by increasing levels of physical activity and reducing rates of obesity in our society.

Azeem Majeed professor of primary care University College London, London WC1H 9QU a.majeed@ucl.ac.uk

Angela Newnham senior lecturer in public health medicine

Thames Cancer Registry, King's College, London SE1 3QD

Ronan Ryan research officer

Office for National Statistics, London SW1V 2QQ

Kamlesh Khunti senior lecturer in general practice Department of General Practice, University of Leicester, Leicester LE5 4PW

1 Pinkney J. Prevention and cure of type 2 diabetes. $B M$ 2002;325:232-3. (3 August)

2 Newnham A, Ryan R, Khunti K, Majeed A. Prevalence of diagnosed diabetes mellitus in general practice in Englan and Wales, 1994 to 1998. Health Stat Q 2002;14:5-13. (www.azmaj.org/PDF/Diabetes.pdf (accessed 16 Octobe 2002).)

3 Dr Curran and Partners. Staying healthy. How to stay healthy. Available at: www.claphamhealth.org.uk Healthy.htm (accessed 16 October 2002).

\section{Let's move upstream to obesogenic} environments, please

EDITOR-Another $B M J$ brings yet another editorial on obesity and associated diabetes. Once again there is no reference to the real cause of this problem-obesogenic environments.

Why is it that commentators constantly shy away from digging deeper? Why do they repeatedly refuse to venture upstream? It must be blindingly obvious to everyone by now that there is, and never will be, any conventional medical treatment for obesity or diabetes. Doctors should come clean and tel patients and populations that the cure lies not with medicine but in how our societies are created.

Children are denied vital play space because politicians favour selling play space to developers. Sixty per cent of the green space used for housing in London in the past 10 years came from the sale of playing fields (Open spaces conference, Bankside Trust, London, March 2002). We exclude children's play from our streets by permitting a $30 \mathrm{mph}$ urban speed limit. If we are to encourage an extra 3 miles of walking daily to enable $4 \mathrm{~kg}$ weight loss, reducing the risk of developing diabetes by $58 \%$, then we must create an environment where people are able to walk. It is facile and cruel just to tell people that they must walk more. Healthy people need healthy environments.

Politicians have the central role in creating healthy populations. They should stop pandering to powerful lobbies such as the pharmaceutical, motoring, food, and tobacco industries. If we as doctors do not tell them that they have the prime responsibility for health then they will continue to abuse us by heaping us with impossible responsibilities for changing the health of our nation. When we inevitably fail then they will give us the blame.

General practice in the United Kingdom is currently teetering on the brink of such stupidity in the shape of a new medical contract that will enslave us into performing the impossible tasks of reducing blood pressure/weight/glycated haemoglobin concentrations/cholesterol concentrations, etc. We will soon be shackled to tick box medical consultations stuffing irrelevant data into computers in a pointless and ever increasing spiral of ineffectual intervention while the good that we can do, but which has never been recognised or rewarded, will simply wither and die.

Perhaps the next obesity and diabetes editorial should be commissioned from a sociologist?

Colin Guthrie general practitioner 1448 Dumbarton Road, Glasgow G14 9DW grey triker@hotmail.com

1 Pinkney J. Prevention and cure of type 2 diabetes. BMJ 2002;325:232-3. (3 August)

\section{Many South Asian people probably need pre-diabetes care}

EDITOR-In their editorial Venkat Narayan et al make a case for the American Diabetes Association's recommendation to screen for pre-diabetes in people over $45 .{ }^{1}$ Pre-diabetes is defined as either impaired glucose tolerance (two hour glucose concentration 7.8$11 \mathrm{mmol} / 1$ after a glucose load) or an impaired fasting glucose concentration of 6.1-6.9 mmol/l. Those screening positive are at high risk of cardiovascular diseases and diabetes and therefore would be counselled on weight loss and increasing physical activity.

This recommendation has profound implications for the health care of South Asian populations originating in the Indian 
subcontinent living in urban settings where pre-diabetes is common. ${ }^{2}$

We reported a secondary analysis of the Newcastle heart project based on age and sex adjustment using the standard population of England and Wales on the prevalence of diabetes and pre-diabetes in those aged 25-74 of South Asian ( $\mathrm{n}=680)$, Chinese $(\mathrm{n}=375)$, and white European origin $(\mathrm{n}=824)$. Weighted percentages and unweighted numbers for South Asians show that the prevalence of impaired fasting glucose (138/ $680)$ and impaired glucose tolerance $(140 / 680)$ was $19 \% .^{3}$ The prevalence of pre-diabetes on either definition was $30.5 \%$ $(226 / 680)$. The prevalence of diabetes based on two hour glucose measures was $20.1 \%$ (160/680); on the American criteria, 21.4\% (173/680); and on either, $23.4 \%(189 / 680)$. Only $49 \%(295 / 680)$ of the population had normal glucose tolerance. A programme of care for pre-diabetes would be needed for about half of the South Asian population in the 25-74 age group, a formidable task complicated by issues discussed below.

Narayan et al would prioritise screening in those with a body mass index of 25 or more, a marker of excess adipose tissue. Markers of obesity, including body mass index, do not have equivalence across ethnic groups. ${ }^{4}$ South Asians in the United Kingdom have slightly lower indices but higher waist:hip ratios and greater skinfold thicknesses. Body mass index is not a good indicator of adiposity in South Asians, and a lower cut-off point for being overweight is necessary.

If interventions are to work people need to perceive risk and benefits accurately. In the Newcastle heart project, South Asian women's perceptions of their own weight did not match guidelines on being overweight and obese. ${ }^{5}$ A substantial proportion of overweight South Asian women perceived themselves to be of normal weight, but women of European origin had the opposite problem. South Asians' knowledge of the causation and prevention of diabetes and heart disease in nearby South Tyneside was poor.

Finally, lack of physical exercise poses a huge challenge (reference available at bmj.com/cgi/eletters/325/7361/403\# 25585). Although the task of halting the process of pre-diabetes becoming diabetes is urgent, careful evaluation of screening and interventions is essential.

R Bhopal Bruce and John Usher professor of public health

C M Fischbacher clinical research fellow

Division of Community Health Sciences (Public

Health Sciences), University of Edinburgh,

Edinburgh EH8 9AG

We thank Dr Nigel Unwin for helpful advice in preparing this letter.

1 Venkat Narayan KM, Imperatore G, Benjamin SM, Engelgau MM. Targeting people with pre-diabetes. $B M$ J 2002;325:403-4. (24 August.)

2 Bhopal RS, Unwin N, White M, Yallop J, Walker L, Albert KGMM, et al. Heterogeneity of coronary heart disease risk factors in Indian, Pakistani, Bangladeshi, and Europ factors in Indian, Pakistani, Bangladeshi, and European origin population
3 Unwin N, Alberti KGMM, Bhopal R, Harland J, Watson W, White M. Comparison of the current WHO and the new ADA criteria for the diagnosis of diabetes in three ethnic groups in the UK. Diabet Med 1998;15:554-7.

4 Patel S, Unwin N, Bhopal R, White M, Harland J, Ayis, SA, et al. A comparison of proxy measures of abdominal obesity in Chinese, European and South Asian adults. Diabe Med 1999;16:853-60.

5 Patel S, Bhopal R, Unwin N, White M, Alberti KG, Yallop J Mismatch between perceived and actual overweight in diabetic and non-diabetic populations: a comparative study of South Asian and European women. J Epidemiol Community Health 2001:55:332-3.

\section{Women with gestational diabetes should be targeted to reduce cardiovascular risk}

EDITOR-Sattar and Greer discuss the probability that complications in pregnancy may predispose women to vascular and metabolic disease in later life. ${ }^{1}$ The link between pregnancy complications and coronary heart disease remains unexplained. We believe that during pregnancy the hormonal and other stresses provoke cardiovascular and metabolic abnormalities in susceptible individuals, which may recur and become permanent as the patient ages. Many of these are coronary risk factors; disturbances in glucose metabolism, which underlie the development of gestational diabetes, are a good example.

An uncomplicated pregnancy is characterised by obvious changes in lipid metabolism early in pregnancy. ${ }^{2}$ These include the formation of small, dense subfractions of
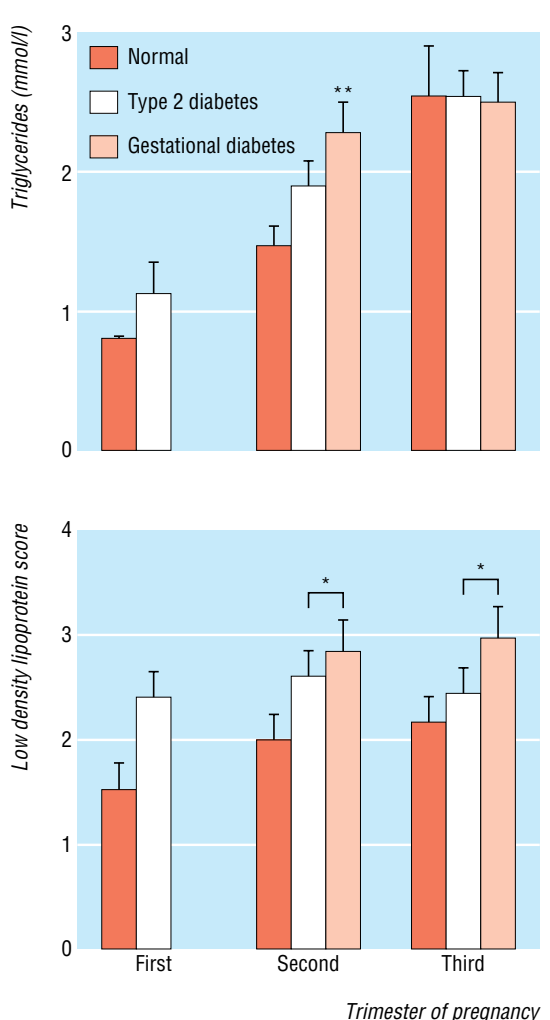

Triglyceride concentrations and low density lipoprotein score during pregnancy in normal controls and women with type 2 or gestational diabetes. ${ }^{\star} P<0.05$, ${ }^{\star \star} \mathrm{P}<0.01$ compared with normal pregnancy low density lipoprotein, an important risk factor for atherosclerosis. ${ }^{3}$ These are retained in the arterial intima, are more easily oxidised, and once oxidised are rapidly taken up into macrophages, creating foam cells and atherosclerotic plaques. The additional effect of pregnancy on lipid metabolism in people with diabetes and those at increased risk of developing diabetes may markedly increase cardiovascular risk in these women.

We recently studied three groups of pregnant women: healthy controls $(\mathrm{n}=17$, mean age 29.2 (SD 1.1 years)), women with type 2 diabetes $(\mathrm{n}=12$, mean age 32.5 (1.6) years), and women with gestational diabetes mellitus ( $\mathrm{n}=12$, mean age 32.8 (1.5) years). Venous blood was taken during each trimester (first, 1-13 weeks; second, 14-27 weeks; and third, 28 weeks to term). Samples were analysed for subfractions of low density lipoprotein (polyacrylamide gel electrophoresis) and triglycerides. A score for low density lipoprotein was calculated from the area under the curve for each subfraction; the higher the score the smaller, denser and more atherogenic the low density lipoprotein particles. ${ }^{4}$

Triglyceride concentrations increased throughout pregnancy in all groups. This was most obvious during the second trimester in women with gestational diabetes (figure). Low density lipoprotein score progressively increased throughout pregnancy, implying the formation of potentially atherogenic lipoproteins. These changes were exaggerated in women with type 2 diabetes but more particularly in those with gestational diabetes (figure).

We found that pregnancy and diabetes have an additive effect on the development of an atherogenic lipid profile. Importantly, this is exaggerated earlier in pregnancy in gestational diabetes. This finding may identify women who are particularly susceptible to the premature development of atherosclerosis. We agree with Sattar and Greer that women with gestational diabetes should be targeted during and after pregnancy with advice on diet and lifestyle to try to modify this excess cardiovascular risk.

V Toescu research associate

v.toescu@bham.ac.uk

S L Nuttall postdoctoral fellow

M J Kendall

professor of clinical pharmacology

U Martin senior lecturer in pharmacology

F Dunne senior lecturer in medicine

Division of Medical Sciences, Queen Elizabeth

Hospital, Birmingham B15 2TH

1 Sattar N, Greer IA. Pregnancy complications and maternal cardiovascular risk: opportunities for intervention and screening? BMJ 2002;325:157-60. (20 Julv.)

2 Toescu V, Nuttall SL, Martin U, Kendall MJ, Dunne F. OxiToescu V, Nuttall SL, Martin U, Kendall MJ, Dunne F. Oxi-
dative stress in normal pregnancy. Clin Endocrinol 2002 (in press).

3 Musliner TA, Krauss RM. Lipoprotein subspecies and risk of coronary disease. Clin Chem 1988;34:B78-83.

4 Rajman I, Kendall MJ, Cramb R, Holder RL, Salih M, Gammage MD. Investigation of low density lipoprotein subfractions as a coronary risk factor in normotriglyceridaemic men. Atherosclerosis 1996;125:231-42 


\section{The global response to mental illness}

First line care facilities and support for providers have to be improved

EDITOR-Thornicroft and Maingay highlight the inadequacy of international responses to mental illness. ${ }^{1}$ In low income countries the burden of mental illness is amplified by financial insecurity, poverty, and partition of families, if not by violence and war. Prevention in mental health is intimately linked with overall human development. Individual care is also necessary. In some societies religious or traditional healers still provide culturally relevant and socially acceptable responses to problems labelled as mental illness. Nevertheless, mental suffering is manifest among users of modern medical services, where it goes largely unrecognised.

Besides poor availability of drugs, human resources are of utmost importance in understanding the apparent neglect of mental health problems. Doctors and nurses in low income countries are often described as rude to their patients, ${ }^{2}$ partly because they have low salaries and poor professional perspectives, which affects their morale, self confidence, and dedication. ${ }^{3}$ Some have problems similar to those of their patients-for example, domestic violence or living with HIV. Some are not prepared to face the emotional burden of listening to patients' suffering. Adequate professional support is unusual, and dealing with emotions is seldom valued by the organisational culture. ${ }^{4}$

If health care in low income countries is to be oriented towards more biopsychosocial approaches, efforts have to include improving first line care facilities and support for providers. Well functioning first line facilities are crucial to integrate mental health programmes accessible to the population. This does not rule out specialised services, but these tend to remain concentrated in cities and are often of limited accessibility financially. In the case of mental health services, stigmatisation furthermore limits their acceptability to potential users.

The integration of mental health programmes in first line care facilities should of course not be detrimental to the comprehensive character of the service delivered. The purpose is not to divert available resources to serve a specific programme but to take advantage of the existing relations between a service and a community to widen the scope of responses provided locally. Health care in low income countries is increasingly thought of as a series of vertical programmes, so the need for access to regular health care is crucial, and specific programmes must strengthen general services rather than weaken them. Indeed, mental health programmes may improve first line care. Concerns for mental health are likely to promote listening skills, to foster patient centred care, and to broaden the professional identities of care providers, cur- rently focused on biomedical issues. This could be an important step on the way to quality general practice adapted to social and cultural contexts.

Monique Van Dormael lecturer mvd@itg.be

Jean-Pierre Unger senior lecturer

Institute of Tropical Medicine, Public Health Department, Nationalestraat 155, 3000 Antwerp, Belgium

1 Thornicroft G, Maingay S. The global response to menta illness. BMJ 2002;325:608-9. (21 September.)

2 Jewkes R, Abrahams N, Mvo Z. Why do nurses abuse patients? Reflections from South African obstetric service. Soc Sci Med 1998;47:1781-95.

3 Segall M. Human development challenges in health car reform. Studies in Health Services Organisation and Polic $2000 ; 16: 7-17$

Van Balen H, Van Dormael M. Health service professionals and users. Int Soc Sci J 1999;313-26.

5 Unger J-P, Van Dormael M, Criel B, Van der Vennet J, De Munck P. A plea for an initiative to strengthen family medicine in public health care services of developin countries. Int J Health Serv 2002;32:799-815.

Focus on mental health means new opportunities for developing countries

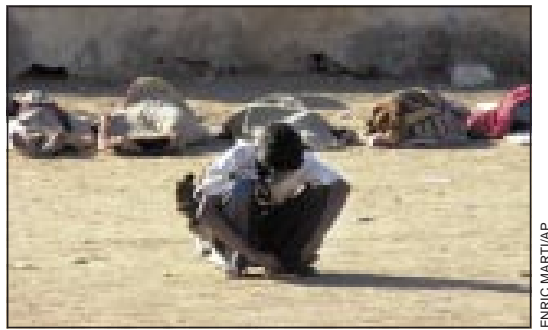

After the Gujurat earthquake

EDIToR-The global resources for mental health raise two issues. ${ }^{1}$ Crisis results from the low priority given to and the limited resources for mental health care. However, the focus on mental health by the World Health Organization offers a new opportunity for developing countries to organise mental health using current knowledge.

Developing countries have four advantages: most ill people live in the community and are cared for by family members families continue to feel directly responsible for care and support, which is an advantage in organising services; the lack of an extensive mental health infrastructure (specialists, specialist beds, different professionals, etc) means that services can be organised using community resources; and greater acceptance of patients by the community allows for easier community involvement in mental health care.

Mental health care has been integrated with primary health care in India and Iran. In India, initiatives began in 1975 and led to the development of a district mental health model (1-2 million population). ${ }^{2}$ This model has now been implemented in 25 districts and is expected to be extended to 100 districts in the next five years (about 150 million population). In Sri Lanka, the amount of training in psychiatry for undergraduates (two full months) has increased and psychiatry is now an examination subject in the final year. The family movement is taking shape in developing countries, and this is fostering new partnerships. ${ }^{3}$ Massive disasters such as the Gujurat earthquake and the Orissa supercyclone have led to the development of a community based psychosocial care with community volunteers. ${ }^{45}$ Similar developments are occurring in many countries of Asia, Africa, and South America.

The development of mental health care faces special challenges in developing countries. These are the need for mental health professionals to shift from a clinical to a public health focus; the development of training materials, case records, information systems, and treatment guidelines; the development of support programmes for families; the passing of legislation to protect the rights of mentally ill people and increase access to mental health care; and the availability of adequate numbers of mental health professionals to support, supervise, and guide the new initiatives.

In conclusion, the global situation is a challenge to professionals to think innovatively.

R Srinivasa Murthy professor of psychiatry Nimhans, Box 2900, Bangalore 560029, India murthy@nimhans.kar.nic.in

1 Thornicroft G, Maingay S. The global response to mental illness. BMJ 2002;325:608-9. (21 September.)

2 Chisholm D, Sekar K, Kishore Kumar K, Saeed K, James S, et al. Integration of mental health care into primary health care. Br J Psychiatry 2000;176:581-8.

3 Srinivasa Murthy R. Community resources for mental health care in India. Epidemiologia e Psychiatria Sociale 2000;9:89-92.

4 Srinivasa Murthy R. Disaster and mental health: role of mental health professionals. Indian Journal of Social Work 2000;61:675-92.

5 Kishore Kumar KV, Chandrashekar CR, Choudhury P, Parthasarathy R, Girimaji S, et al. Information manual 2. Psy chosocial care for community level helpers: supercyclone. Books for Change (Unit of Action Aid Karnataka Projects), 2000.

\section{Discontinuation of thioridazine}

\section{Risks must be balanced}

EDITOR-Until the Committee on the Safety of Medicines restricted the use of thioridazine in 2000 , it was the most widely used antipsychotic drug in the United Kingdom, with 50 million years of safe use by patients worldwide. In Scotland in 1999, were 250808 were prescriptions dispensed in primary care (hospital data not available, but the safety committee reports that it was the most widely used antipsychotic drug in hospitals too). This dropped to 39177 in 2001, according to information from the Primary Care Information Unit in Edinburgh.

Is thioridazine safer, cheaper, and more effective than alternative antipsychotic drug treatments for anxiety, agitation, mania, and hypomania? We do not have enough evidence to answer this because thioridazine has been widely used for 30 years-before the days of rigorous randomised controlled trials. Lack of evidence is not evidence of no benefit. Conversely, there is only evidence of a handful of adverse cardiac events, some of which may not have been directly caused by thioridazine or may have been due to combination with other drugs. Although the reported cardiac deaths are lamentable, it 
seems that thioridazine is much safer than other effective drugs such as aspirin, which continues to be sold over the counter. Even if adverse events are under-reported, there is far more practical evidence of long term safety for thioridazine compared with much more expensive and much less tried and tested drugs. A recent study noted that many new drugs have a high rate of serious side effects which go undetected until late in postmarketing surveillance. ${ }^{2}$ The Committee for the Safety of Medicines needs to balance these relative risks.

The manufacturers of thioridazine have raised few objections to the restricted use of thioridazine because it is an extremely cheap drug, costing only a few pence compared with newer antipsychotics that may be up to a hundred times more expensive, as well as having different and sometimes distressing side effects. The prescription costs of antipsychotic drugs has risen sharply in Scotland in the past two years.

Anecdotally, considerable numbers of patients with hypomania, anxiety, and agitation are having considerable problems in adjusting to a change of drugs, and, as Davies et al point out, informed consent may be a problem. ${ }^{1}$ It would be very helpful if the National Institute for Clinical Excellence or Health Technology Board for Scotland reviewed the evidence, risks, and benefits of thioridazine, and considered more humane guidelines for its future use. It seems quite wrong to deprive so many patients of a well tried drug.

Ann F Bisset medical adviser

Public Health Medicine, Information and Statistics Division, Edinburgh EH5 3SQ

ann.bisset@virgin.net

Competing interests: None declared.

1 Davies SJC, Cooke LB, Moore AG, Potokar J. Discontinuation of thioridazine in patients with learning disabilities: balancing cardiovascular toxicity with adverse consequences of changing drugs. BMJ 2002:324:1519-21. (22 June.)

2 Lasser KE, Allen PD, Woolhandler SJ, Himmelstein DU, Wolfe SM, Bor DH. Timing of new black box warnings and withdrawals for prescription medications. JAMA 2002: 287:2215-20

\section{What happened to thioridazine?}

EDITOR-The article by Davies raised some important issues on discontinuation of thioridazine in populations with learning disability. ${ }^{1}$ We had successful withdrawal of thioridazine in our services in Salford district.

We looked at the following issues before withdrawal of thioridazine:

(1) Initial diagnosis before thioridazine was prescribed

(2) Duration and dose of treatment

(3) Review of previous psychiatric treatment including attempts to reduce or stop thioridazine.

Results indicated that 28 out of 175 patients under the care of a psychiatrist specialising in learning disability received thioridazine. Twenty three patients received small doses $(50-100 \mathrm{mg})$ for many years. The main indication for use was marked challenging behaviour (12 patients). Based on the above information, a decision was made to gradually reduce (12 patients) or suddenly stop thioridazine (16 patients)

As an alternative, a tranquilliser was prescribed for all 28 patients. Risperidone was the most commonly used atypical antipsychotic drug because of some evidence of its effectiveness in challenging behaviour. ${ }^{2} \mathrm{~A}$ review of patients' mental state three months after the substitution of tranquillisers indicated that twenty one patients either remained stable or improved, and seven patients deteriorated. These seven patients subsequently improved, either by a change to a different psychotropic drug or by adjusting the dose of existing drugs. No patient needed to restart taking thioridazine.

Review of previous psychiatric treatment helped us to identify instances of rebound increase in behavioural problems when thioridazine was stopped. It also prompted us to avoid using neuroleptics that were either ineffective or caused unacceptable side effects. Evidence of rebound aggression on stopping neuroleptics was also observed by Mos et al. ${ }^{3}$ This lead us to withdraw thioridazine gradually in most cases.

In our opinion risk associated with the withdrawal of thioridazine was managed carefully and minimised by taking into account the diagnosis, the dose and duration, and consequences of previous reduction in medication followed by a careful strategy of either gradual reduction or sudden stoppage with replacement of alternative tranquillisers in appropriate doses.

Pernia Arshad consultant in learning disability psychiatry

sridhar777@yahoo.co.uk

Mary Morcos senior house officer in psychiatry Baskaran Sridharan specialist registrar in psychiatry Department of Psychological Medicine, Meadowbrook Unit, Salford M6 8HG

Competing interests: None declared.

1 Davies SJC, Cooke LB, Moore AG, Potokar J. Discontinuation of thioridazine in patients with learning disabilitie balancing cardiovascular toxicity with adverse consequences of changing drugs. BMJ 2002:324:1519-21. (22 June.)

2 Vander Ben Borre R. Risperidone as add-on therapy in behavioural disturbances in mental retardation: a double blind placebo-controlled cross-over study. Acta Psychiatrica Scandinavica 1993:87:167-71.

Mos J, Van Aken HH, Van Oorschot R, Olivier B. Chronic reatment with eltoprazine does not lead to tolerance in is anti-agoressive actions, in contrast to haloperidol. Ear Neuropsychopharmacol 1996;6:1-7.

\section{Temple healing}

\section{Healing temples may breed superstitions}

EDITOR-Raguram et al report that when patients with psychiatric disorders stay briefly at a healing temple most of them improve significantly. ${ }^{1}$ They describe at length the legend of Muthuswamy and endorse the local notion that the temple is endowed with mysterious healing power.

This suggestion could leave unwary patients with an unjustifiably favourable impression that healing temples can cure their diseases. Most Indians are deeply

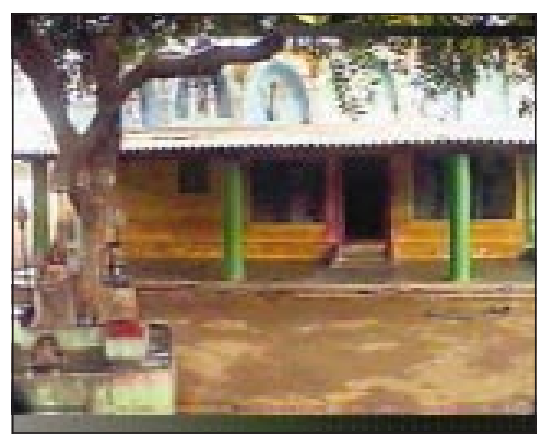

Muthuswamy temple

religious and superstitious. In Indian villages myths, misconceptions, blind beliefs, and superstitions abound. Quacks and local healers thrive on the illiteracy and ignorance of naive and gullible people and try to hoodwink them into believing that they have magic cures for their ills.

Muthuswamy temple might be an exception, for it does not charge people who stay there, and, more importantly, offers no specific healing rituals. But local newspapers and quacks may distort the conclusions of the study by pointing out that even a Western journal recognises-and endorsesthe hidden healing powers of Indian temples. The news might make thousands of people seek a cure for their chronic diseases in temples and shrines. Even people with potentially curable diseases may choose not to see doctors in the hospitals but seek shelter in holy places. The consequences of such an attitude could be terrible.

History tells us that when tuberculosis was a formidable foe in the 19th century people thought that their best chance of conquering the disease was residing in a sanatorium. ${ }^{2}$ Patients and their doctors all over the world believed that a salubrious environment, clear mountain air, and nutritious food was the best way to ensure cure. Thousands of patients with tuberculosis chose Switzerland as their health destination. Myths were woven around sanatoriums, and people who could afford it resided in what they considered "magic mountains" for as long as 10 years.

The sanatorium made most patients feel better for a while, but their infection progressed unabated and killed all of them. Doctors and lay people took 75 years to realise that sanatorium was a highly expensive-and terribly ineffectiveintervention for getting rid of tuberculosis.

I think healing temples for alleviating psychiatric disorders and magic mountains for curing tuberculosis share one thing: a strong placebo effect fostered by local superstitions and traditions. Patients with chronic and psychiatric diseases often do not go to their doctors, but we should avoid creating an impression among the public at large that healing temples are capable of restoring their health.

$\mathbf{S} \mathbf{P}$ Kalantri professor of medicine

Mahatma Gandhi Institute of Medical Sciences, Sevagram 442102, India

sp_kalantri@rediffmail.com 
1 Raguram R, Venkateswaran A, Ramakrishna J, Weiss MG. Traditional community resources for mental health: a report of temple healing from India. BMJ 2002;325:38-40. (6 July.)

2 Reichman LB, Tanne JH. Timebomb: the global epidemic of multi-drug resistant tuberculosis. New York: McGraw Hil Press, 2002:20-21.

\section{Spiritual care is important}

EDITOR-As a senior house officer in an acute psychiatric ward in central London, I can understand why there was improvement in the condition of the psychiatric patients who resided in the Muthusamy temple in India, as reported by Raguram et al. ${ }^{1}$ Patients were brought into a place of "refuge" with people similar to them, who understood their condition. This would result in less expressed emotion and distress and better care of the individual, not only by relatives but also by temple staff in a supportive, nonthreatening environment. Here people can make sense of their mental illness. This is good "psychosocial" psychiatric care.

How does this contrast with an acute psychiatric ward? Patients are placed in a busy and emotionally charged environment with others who may be more disturbed, usually with little support from relatives. Relatives' visiting rights are limited, and patients may not have anyone to confide in. Here there is good "biological" psychiatric care, with emphasis on psychotropic drug treatment

What is the way forward? We need a more holistic approach to inpatient psychiatric care to try to "heal" our patients, rather than just treat their psychopathology. Family members need to be fully involved. For serious mental illness, the individual's spiritual needs, which are important to most people, must be looked after. The power of cultural beliefs and spirituality is important, as seen by belief in the healing power of the temple, and this is largely neglected in modern psychiatry. ${ }^{2}$ The result is increased stigmatisation of psychiatric wards, which are viewed more as places of containment than refuge.

What would have happened if Raguram et al distributed psychotropic drugs to the patients at the temple? I am sure their condition would improve more quickly as there would be "holistic biospychosocial healing." I hope for the day when psychiatric temples, or places of worship, without stigma and with a cultural belief of healing, will replace psychiatric wards. Then holistic biopsychosocial care of mental illness can truly be achieved.

Cyrus A Abbasian senior house officer York Clinic, Guy's Hospital, London SE1 3RR abbasian@hotmail.com

1 Raguram R, Venkateswaran A, Ramakrishna J, Weiss MG Traditional community resources for mental health: a report of temple healing from India. BMJ 2002;325:38-40. (6 July.)

2 Culliford L. Spiritual care and psychiatric treatment, an introduction. Adv Psychiatr Treatment 2002;8:249-61.

\section{Author's reply to responses}

EDITOR-Our study was motivated by previous clinical cultural epidemiological research on schizophrenia in Bangalore, India. Traditional sources of help, such as local healers and healing temples, figured prominently in patients' previous help seeking, which suggested that research was needed to examine their experiences at healing temples more closely.

We reported improvement in symptoms, and these findings were as surprising to us as to many readers of the article. But we recognised the diversity of practices used in various settings of traditional healing and emphasised that benefits documented at one site should not be generalised to all healing temples and that our findings should not be construed as professional endorsements of diverse traditional healing practices.

Nevertheless, our study does indicate the value of traditional community resources in caring for serious, chronic mental illnesses and shows the effect of a supportive environment that derives its healing power from the cultural values of the community. Inasmuch as such environmental supports may be lacking in many institutions for mental health care, we should welcomerather than fear misuse of-such healing contexts. Moreover, pertinent social supports and cultural influences may profitably complement psychopharmacological and neurophysiological frameworks that guide effective psychiatric practice.

Larger questions about the impact of the sociocultural context of mental health care for people with chronic mental illness in India also motivated our study. Policy making and plans for community programmes should benefit from consideration of the nature of the existing local system which planned interventions may try to replace or complement. For that, research should attend to two broad aims.

Firstly, an assessment of the impact of traditional healing is needed with reference both to local and professional criteria, as reported in our article.

Secondly, the cultural epidemiology of mental health problems-with reference to their local experience, meaning, and behaviour-is also needed. Findings have been presented in a thesis by Venkateswaran (2001) and will be elaborated elsewhere.

With appreciation of growing interests in complementary approaches to health care, and recognising the importance of attention to sociocultural contexts for effective community mental health planning, scientific studies are both warranted and needed. They encourage an ongoing process of critical rethinking to ensure the relevance of psychiatric practice locally and to enhance the acceptance and effectiveness of community mental health programmes.

R Raguram professor of psychiatry

Department of Psychiatry, National Institute of Mental Health and Neurosciences, Bangalore 560029 , India

\section{Primary prevention strategies for cardiovascular disease}

EDITOR-The assumptions made by Marshall and Rouse in their study are too broad and may lead to erroneous conclusions. Using the Framingham equation with average values is going to stratify the population only by age, sex, and diabetes status. Such stratification is simplistic and will prove only that older people and people with diabetes are more at risk. By assuming the subjects are non-smokers Marshall and Rouse exclude the most important single weighting in the Framingham calculation. Most practices have a register of smoking status for most of their patients, so this should be included.

Marshall and Rouse admit that their method may not be able to screen all of the population, so some will lose out. By concentrating on the oldest patients and patients with diabetes first, it will not detect some who have most to lose, such as 50 year old smokers with hypercholesterolaemia and hypertension. Adding a few extra years to the life of a 70 year old non-smoking normotensive diabetes patient may be laudable, but just because it is easier and cheaper does not mean that these patients should be prioritised to be assessed first, as this method seems to suggest.

Many of Marshall and Rouse's other assumptions do not fit well with the day to day realities of general practice. Few general practitioners would be able to stabilise antihypertensive treatment with only four prescriptions and two follow up consultations in a year. Government policy is to issue 30 days' supply, so Marshall and Rouse underestimate dispensing costs. Not all of this work can or should be done by practice nurses. Other diagnoses will be found requiring medical intervention, and many patients need more careful clinical assessment than a simple protocol provides. Marshall and Rouse's assumption that two 20 minute consultations by a practice nurse are all that is needed to treat is wrong, so their economic argument is flawed.

Their conclusion about statins and angiotensin converting enzyme inhibitors costing more, so strategies avoiding these may allow more disease to be prevented is odd. It would be actionable to omit a cholesterol measurement on a high risk patient or if a high level was found, negligent not to treat. Avoiding them is not an option in the real world.

This paper adds little to the subject other than confusing people into thinking there is a quick and cheap method of cutting short the hard and expensive, but necessary, work of finding all those at risk of heart disease and lengthening their lives.

Gill Tyerman general practitioner

Peter Tyerman general practitione

Rotherham Road Surgery, Barnsley S71 1UT

Trefor J Roscoe general practice informatics tutor, North Trent

Institute of General Practice, Northern General Hospital, Sheffield S7 1AU

1 Marshall T, Rouse A. Resource implications and health benefits of primary prevention strategies for cardiovascular diseases in people aged 30-74: mathematical modelling study. BMJ 2002;325:197-202. (27 July.) 


\section{Authors' reply}

EDITOR-Our principal conclusion has not been challenged: authors of guidelines should explicitly model the resource implications and health benefits of following their recommendations. The table shows the results of modelling using Tyerman et al's suggestions: 12 prescriptions a year, all assessment and follow up by doctors, patient assessment taking 1 hour, stabilisation and follow up taking 2 hours over five years. A practice that preselects 200 patients to assess prevents $82 \%$ as much cardiovascular disease at $57 \%$ of the cost.

Simvastatin costs more and is less effective than identifying and treating new patients with aspirin and antihypertensive drugs. Five years' treatment with simvastatin $10 \mathrm{mg}$ costs $£ 1175$. Five years of aspirin, atenolol, and hydrochlorothiazide, is $£ 718$, including staff costs. The relative risk of cardiovascular disease with statin treatment is 0.7 , with aspirin and antihypertensive drugs $0.6 \quad(0.8 \times 0.75=0.6)$. This will be explored further in a future paper.

We agree that there is an unresolved dilemma in cardiovascular prevention. A clinician acting in the best interests of an individual patient prescribes a statin; a clinician acting in the best interests of the whole practice population does not but employs a practice nurse to find and treat more patients. The former is consistent with the clinician's duty of care but is a poor prevention policy. The latter is consistent with the optimum use of public funds.

We can also model the implications of Tyerman et al's preference for prioritising 50 year olds over 70 year olds. For 50 and 70 year old men life expectancy is 25 years and 11 years, respectively, and cardiovascular mortality (per 10000 ) is 12 and $111 .^{1}$ Per 10000 people, cardiovascular disease therefore accounts for 312 and 1243 lost years of life in 50 and 70 year old men. We therefore can potentially add four times more years to life in 70 year olds than in 50 year olds. This is not necessarily irrational. Only a rational decision maker who valued the life years of 50 year olds four times more than those of 70 year olds would prioritise the younger men over the older ones.

We agree that information on smoking should be included when calculating prior risk estimates. This would improve the accuracy and efficiency of preselection. However, risk factor recording is not universally accurate, ${ }^{2}$ so we modelled our approach in a

Resource implications and health consequences of cardiovascular disease prevention with Tyerman et al's suggestions

\begin{tabular}{|c|c|c|c|c|c|}
\hline \multirow{2}{*}{$\begin{array}{l}\text { No of } \\
\text { patients } \\
\text { assessed }\end{array}$} & \multirow{2}{*}{$\begin{array}{l}\text { No of patients } \\
\text { eligible for any } \\
\text { drug treatment }\end{array}$} & \multicolumn{2}{|c|}{ Workload (h) } & \multirow{2}{*}{$\begin{array}{l}\text { Benefit: CVD events } \\
\text { prevented per } 5 \text { years }\end{array}$} & \multirow{2}{*}{$\begin{array}{c}\text { Cost per } 5 \text { years } \\
(£)\end{array}$} \\
\hline & & Assessment clinic & Follow up clinic & & \\
\hline 100 & 75 & 100 & 50 & 6.7 & 145735 \\
\hline 200 & 113 & 200 & 75 & 9.2 & 222967 \\
\hline 300 & 135 & 300 & 90 & 10.3 & 269687 \\
\hline 400 & 147 & 400 & 98 & 10.8 & 301094 \\
\hline$\overline{939}$ & 163 & 939 & 108 & 11.2 & 389099 \\
\hline
\end{tabular}

$\mathrm{CVD}=$ cardiovascular disease.

practice with the bare minimum of electronically recorded data.

With our preselection strategies, a woman's cardiovascular risk is equivalent to that of a man 12 years her junior. A good approximation of our preselection rankings is obtained by assigning a ranking number to every patient. For men it is their age, for women their age minus 12 . Patients are prioritised for cardiovascular risk assessment by their ranking number (highest number first).

\section{Tom Marshall lecturer}

Andrew Rouse senior lecturer

Public Health and Epidemiology, University of

Birmingham, Birmingham B15 2TT

1 Office for National Statistics. Mortality data from England and Wales in 2000. London: Stationery Office, 2000. (www statistics.gov.uk/statbase/Product.asp?vlnk=618\&More $=\mathrm{N}$ accessed 2 August 2002.

2 Mant J, Murphy M, Rose P, Vessey M. The accuracy of general practitioner records of smoking and alcohol use: comparison with patient questionnaires. J Public Health Med 2000;22:198-201.

\section{Risk:benefit ratio is important in treating atopic dermatitis}

EDITOR-Williams acknowledges the efficacy of tacrolimus and pimecrolimus in atopic dermatitis but subsequently his editorial is negative and lacks any patient perspective. ${ }^{1}$ The issue lies not in clinicians' disembodied comparisons of efficacy but in what treatment provides patients, or their affected children, with the most acceptable benefit:risk ratio.

Only $40 \%$ of patients with eczema are reportedly satisfied with their treatment, and work from Williams's own department has shown that in many cases using a topical corticosteroid produces risks, especially of skin thinning, which are unacceptably high to the patients, resulting in non-compliance and inadequate treatment. ${ }^{2}$

Patients' fears about steroids can hardly be dismissed as irrational, even though they may be exaggerated. Far from being rare, the risks of adverse events from the use of steroids are directly related to the duration, quantity, and potency of the steroid used. Thus today's patients are just as much at risk as before unless they choose to endure the misery of their condition and leave it undertreated. The main fear which patients had was of skin thinning. Topical tacrolimus and pimecrolimus are free of this and other risks associated with steroid use and offer a realis- tic alternative of proved efficacy whatever their potencies relative to each other or to corticosteroids.

Although the editorial declares the use of probiotics harmless, the long term risks of using such strategies are currently unknown and the subject of debate. ${ }^{3}$ Their safety has not been tested on anything like the 13000 included in the trials of tacrolimus and pimecrolimus.

As with any new treatment, close monitoring will be mandatory, but longer term studies with pimecrolimus and tacrolimus show no clinically significant increase in infections or skin cancers. ${ }^{45}$ Since the drugs are non-mutagenic, are absorbed only slightly, and do not permanently impair primary immune responses, an increased risk of cancer either topical or visceral is most unlikely. It is of note that with over 40 years of use of potent topical steroids-which not only deplete cutaneous Langerhans cells but are highly immunosuppressant as well as being systemically absorbed-there is no evidence that they predispose to cancer either cutaneous or systemic. These new drugs for atopic dermatitis are welcomed by patients, parents, and doctor as a wholly new treatment option for this demoralising disease. They are the first major advance in its management in half a century.

B Roger Allen consultant dermatologist Department of Dermatology, University Hospital, Queen's Medical Centre, Nottingham NG11 6QU brallen1@aol.com

\section{Thomas A Luger}

Department of Dermatology, Westphalian Wilhelms-University of Münster,

Von-Esmarch-Strasse 56, D-48149 Münster, Germany

luger@uni-muenster.de

The authors have received funding from Fujisawa and Novartis to advise on and carry out clinical studies on tacrolimus and pimecrolimus.

1 Williams H. New treatments for atopic dermatitis. BMJ 2002;324:1533-4

2 Charman CR, Morris AD, Williams HC. Topical corticosteroid phobia in patients with atopic eczema. $\mathrm{Br} J$ Dern 2000;142:931-6.

3 Murch SH. Toll of allergy reduced by probiotics. Lancet 2001:357:1057-8

4 Wahn U, Bos JD, Goodfield M, Caputo R, Papp K, Manjra A, et al. Efficacy and safety of pimecrolimus cream in the long-term management of atopic dermatitis in children. Pediatrics 2002;110:1-8.

5 Kang S, Lucky AW, Pariser D, Lawrence I, Hanifin JM. Long-term safety and efficacy of tacrolimus ointment for the treatment of atopic dermatitis in children. $J$ Am for Dermatol 2001;44(suppl 1):S58-64.

\section{Using evidence based tools to manage chronic illness}

EdiToR-Von Korff et al discussed how to organise care for chronic illness. ${ }^{1}$ Since 1993 we have used evidence based care tools that combine patients' needs, values, and perceptions with scientifically valid patient based assessments to measurably improve and maintain health related quality of life.

We routinely use the functional health assessment questionnaire (SF-36) and the Zung depression, Beck anxiety, and Epworth sleepiness scales. We integrate these data with patient self care data 
(reports on weekly exercise, self monitoring of blood pressure, breast self examination, seat belt use while driving, etc) and condition specific data (glycated haemoglobin concentration, cardiac risk index, $\mathrm{T}$ scores on bone densitometry, ejection fraction on cardiac echocardiography, etc).

The process is appealing in both prepaid and self payment health care because the health strategy can be tailored, focusing on the patient's concerns and needs first and including any remaining concerns from practitioners. Clients enter the integrative health process through an initial integrative health consultation. The SF-36 is used as the baseline measure of quality of life. It contains scores summarising both physical and mental function and eight subscales (physical functioning, role physical limitations, bodily pain, general health perception, vitality, social function, role emotional limitations, and mental health).

A standardised interview identifies patients' perception of why they are underfunctioning as well as their perception of what is necessary to bring their experience of health to a place of excellence. We keep the clients engaged by addressing both their pain and their hopes simultaneously in one strategic plan.

We are in the process of refining our collaborative methods for displaying trends during telephone conferences with a group of focused, local health practitioners and, when necessary, the patient and a family member. Such a care conference would allow evaluation of trends and modification of the strategic plan as needed. Our principal challenge has been technological. These methods will be widely accessible when simple communication, assessment, and reporting technology becomes practical, affordable, and available to busy practitioners.

Dwana M Bush family physician Integrative Health Institute/Atlanta Family Medicine, Atlanta, GA 30342, USA

dbush@integrativehealth.com

1 Von Korff M, Glasgow RE, Sharpe M. ABC of psychological medicine: organising care for chronic illness. BMJ 2002;325:92-4. (13 July.)

\section{Criticism of new German chronic disease management is unfair}

Editor-Tuffs' news item on the new chronic disease management programmes in Germany is misleading.

The new programmes have arisen from economic analysis showing the importance of ensuring that health insurance funds should not continue to be penalised financially when they have large numbers of patients with chronic diseases.

The economic rationale for these programmes is not simply to fund deficits. There will be no extra money put into the system. Instead the existing risk adjustment strategy will take the higher costs for patients with chronic disease (initially type 2 diabetes and breast cancer) directly into account. Ultimately the government hopes to implement a new risk adjustment model that takes account of all pre-existing morbidity.

The federal government's new programmes have arisen after the latest report of the Sachverständigenrat (the government's advisory council) using data from the Organisation for Economic Cooperation and Development (OECD). Germany has the highest health expenditure in Europe with questionable quality of care. The programmes aim to eliminate overuse, underuse, and misuse of care.

The German Medical Society, statutory health insurance physicians, the hospitals society, and health insurance companies participated in the working group and the political committee that recommended these programmes to the government. The physicians could appoint their own experts and agree on all aspects of the programmes. All agreed, except for the hospitals society, which opposed requiring an evidence base for specific drugs. Thus it is hard to understand why the German Medical Society should have agreed on programmes that its president, Jörg-Dietrich Hoppe, now considers meet only minimal standards.

Condemning the new disease management programmes as inferior to routine care is pure polemic. For the first time in German medicine, such programmes have been built on a solid basis of evidence based medicine, combining the best available evidence with clinical expertise.

We conclude that the doctors' opposition to these programmes results from the deep cultural shock felt by those who thought that medical experts could never come into conflict with evidence based medicine, which for the first time has become an integral part of official governmental programmes. Physicians' representatives are also not amused that the health insurance companies showed their willingness to become players rather than just payers in the development of these new disease management programmes.

These programmes will be updated regularly and must go through a tough process of certification and evaluation before they can become part of the risk adjustment mechanism. We strongly believe that they will enable us to overcome the important obstacles that we presently face in providing integrated care for people with chronic diseases.

Norbert Schmacke head

Norbert.Schmacke@bv.aok.de

Jörg Lauterberg vice head

Medical Department, Federal Association of the Local Health Funds (Bonn-Germany), Kortrijker Strasse 1, D-53177 Bonn, Germany

1 Tuffs A. Chronic disease management programmes are criticised by doctors. BMJ 2002;325:356. (17 August.)

\section{Patient education is not a treatment modality}

EDITOR-In their editorial Riemsma et al treat patient education in rheumatoid arthritis as a treatment modality, showing that it produces some minor improvements in a series of outcome measures. ${ }^{1}$

I have some reservations about treating patient education in this way. Providing people with medical conditions with information about their options is now an ethical requirement so that they can give informed consent. In such an uncertain and potentially life threatening and crippling condition as rheumatoid arthritis, health providers must supply as much information as patients require so that they can make the many decisions about their management in an informed way. It is an obligation, not a treatment modality, although knowledge can improve coping mechanisms and help internalise control, which both have beneficial long term effects.

It is also neither efficient nor effective a use of resources to prescribe all patients with a chronic disease such as rheumatoid arthritis counselling or behaviour modification. Armed with the facts from education sessions, many patients work out their own ways of coping and managing their condition, and this will not be improved by either counselling or behaviour modification. Some patients do need counselling to help them accept their condition and its implications and to plan for the future. Others with adverse health beliefs and dysfunctional behaviours will benefit from behaviour modification.

Thus I do not believe that judging these modalities by their effect on every member of a population with rheumatoid arthritis provides a true measure of their worth. Information giving is an ethical obligation. The indications for counselling and behavioural modification can be defined. It is in this group that the placebo clinical trials should be performed.

In this age of cost effectiveness, ethical obligations and modalities that are effective when targeted properly must not be cast away because they are not as effective as drug treatment in a population. They are designed for a different job. Every patient with rheumatoid arthritis would be given a hip replacement by this reckoning, for example.

Jeremy J Jones consultant rheumatologist Ysbyty Gwynedd, Bangor, Gwynedd LL57 2PW jeremy.jones@nww-tr.wales.nhs.uk

1 Riemsma RP, Taal E, Kirwan JR, Rasker JJ. Patient education programmes for adults with rheumatoid arthritis. BMJ 2002;325:558-9. (14 September.)

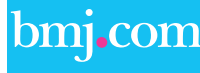

\section{Rapid responses}

Correspondence submitted electronically

is available on our website 